\title{
Design and Analysis of Experiments for a PEM Fuel Cell Mathematical Modelling
}

\author{
A. Crăciunescu ${ }^{1}$, C. L. Popescu ${ }^{1}$, M. O. Popescu ${ }^{1}$, L. Pătularu ${ }^{1}$ and M. Predescu ${ }^{1}$ \\ ${ }^{1}$ Department of Electrical Engineering \\ University "Politehnica" of Bucharest \\ Splaiul Independenței 313 \\ 060042-Bucharest, (Romania) \\ Phone:+4021 4029125, e-mail: aurelian.craciunescu@upb.ro, claudia.popescu@ upb.ro
}

\begin{abstract}
Proton Exchange Membrane (PEM) Fuel Cells are power sources that convert energy of gaseous hydrogen into electric energy. In comparison with usual electrical batteries, PEM Fuel Cells are best suited to applications adaptable to customer demands that involve high power density, stability and prolonged life cycle. From the mathematical point of view, PEM Fuel Cells are a multivariable nonlinear system. Experimental investigation of such as a system considering as many input factors without a proper statistical method could result in hundreds of time-consuming experiments that cannot guarantee an adequate solution. The Design of Experiment provides a very efficient methodology to obtain a mathematical model for the PEM Fuel Cells with only a few experiments. In this paper, the development of a PEM Fuel Cells mathematical model based on the Design of Experiment methodology is described.
\end{abstract}

\section{Key words}

Fuel Cells, Mathematical Models, Design of Experiment.

\section{Introduction}

Figure 1 shows the Voltage-Current characteristic of a Fuel Cell. The PEM Fuel Cell can be operated in different current density regions. From a utilization point of view, the PEM Fuel Cell should operate over the high-output power region, located around the knee of the slow downward portion of the Voltage-Current characteristic. The design goal of this paper is to use a priori experimental information to identify the main input factors that contribute to the PEM Fuel Cells output voltage behaviour in the region of high-output power, where the operation point is expected, and to prepare the appropriate Design of Experiment in order to obtain the mathematical model of the high-output power region. For this, shall be chosen the local region, the basic level and the variation intervals of the input factor [1], [2], [4].

The experiments were performed on a PEM Fuel Cell made with the following components:
- Polymeric membrane with platinum catalyst, the active surface of $92 \mathrm{~cm}^{2}$, capable of working at power density of $0.3 \div 0.5 \mathrm{~W} / \mathrm{cm}^{2}$.

- The gas diffusion layer-type graphite paper Sigracet巴 of $315 \mu \mathrm{m}$ thickness, $75 \%$ porosity and maximum $14 \mathrm{~m} \Omega / \mathrm{cm} 2$.

- The elastomer gaskets with hardness of $35 \pm 5$ Shore A, supported temperatures from minus $40^{\circ} \mathrm{C}$ to plus $120^{\circ} \mathrm{C}$.

- Graphite plates with nominal density of 1.5 $\mathrm{g} / \mathrm{cm}^{3}$, electrical resistivity of $7 \mu \Omega \mathrm{m}(\mathrm{x}-\mathrm{y})$ and $300 \mu \Omega \mathrm{m}(\mathrm{z})$.



Fig. 1 The Voltage-Current characteristic of a Fuel Cell

\section{Preliminary experimental investigations}

Before starting the modelling process, the PEM Fuel Cell must be experimental investigated to a certain extend. The information contained in the results of experimental investigation is called a priori information (i.e. obtained before the beginning of the experiment). This a priory information is used to get an idea of the optimization parameters, of the factors, of the best conditions for conducting the process and the nature of the response surface, i.e. of how greatly the optimization parameter 
varies with small variations in the values of the factors, and also the curvature of the surface. The selection of the experimental region of factor space can be made only after a detailed analysis of a priori information. In the following, some representative results of the preliminary experimental investigation will be given. Factors included in experimental investigations are the mechanical compression of the polymeric membrane and the operating temperature of the cells. Two outputs or responses are considered: output power and output voltage. Both responses are expected to change with a change in any of considered factors. Results of the experimental investigations are given in Figures 2 and 3.



Fig. 2 The influence of mechanical compression of the polymeric membrane at $55^{\circ} \mathrm{C}[3]$

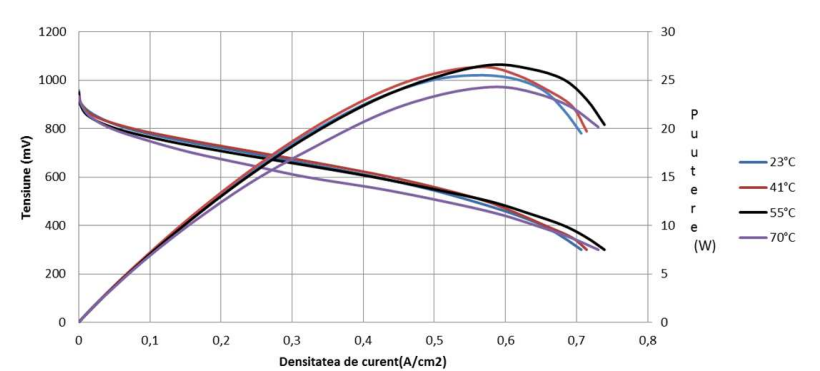

Fig. 3 The temperature influence at $45 \%$ mechanical compression of the polymeric membrane [3]

\section{Factors, Levels and Responses}

It is necessary to find a local sub region for designing an experiment in the region of determination. The procedure for selecting this sub region includes two steps, namely, selection of the basic level and selection of the variation intervals. The factor levels selected after the analysis of the a priori experimental results presented in Figure 2 and 3 are the following:

- For the mechanical compression of the polymeric membrane: $35 \%-45 \%-55 \%$,

- For the temperature of the cell: $40^{0} \mathrm{C}-55^{\circ} \mathrm{C}-$ $70^{\circ} \mathrm{C}$

For the output current of Fuel Cell, considered as an experimental factor, its levels have to be chosen in different region on the current density axis:

- $(0.40-0.45-0.50)$ for the case investigated in Figure 2,

- $(0.50-0.60-0.70)$ for the case investigated in Figure 3.
It should also be noted that for simplifying the recording of the conditions of an experiment and processing of the experimental data, the scales along the axes are so selected that the upper level corresponds to +1 , the lower level to -1 and the basic level to zero. For factors with a continuous determination region, this can always be done with the aid of the transformation:

$$
x_{i}=\frac{X_{i}-X_{\text {imed }}}{X_{\text {imed }}-X_{\text {imin }}}
$$

where: $x_{i}$ is the coded value of the factor, $X_{i}$ is the natural value of the factor, $X_{\text {imed }}$ is the natural value of the basic level, and $X_{\text {imin }}$ is the lower value of the factor.

For factors having two levels, one level is denoted by +1 and the other by -1 . The mathematical model which can be developed taking into account separately, the considered factors and also the output current of the Fuel Cell, will have the following expression [5]:

$$
Y=b_{0}^{\prime}+b_{1} x_{1}+b_{2} x_{2}+b_{11}\left(x_{1}^{2}-\overline{x_{1}^{2}}\right)+b_{22}\left(x_{2}^{2}-\overline{x_{2}^{2}}\right)+b_{12} x_{1} x_{2}
$$

where the coefficients are given by the formula:

$$
b_{i}=\frac{\sum_{u=1}^{N} x_{i u} Y_{u}}{N}
$$

where $N$ is the experiment numbers and $\mathrm{Y}_{\mathrm{u}}$ is the appropriate yield value for each experiment.

The power's response surface in the vicinity of the maximum for current density factor $x$ and mechanical compression factor $y$ has the following mathematical model:

$f(x, y)=b_{0}^{\prime}+b_{1} x+b_{2} y+b_{11}\left(x^{2}-\overline{x^{2}}\right)+b_{22}\left(y^{2}-\overline{y^{2}}\right)+b_{12} x y$.

The mathematical model of the power's response surface for current density factor $z$ and temperature factor $n$ is similar:

$$
h(z, n)=c_{0}^{\prime}+c_{1} z+c_{2} n+c_{11}\left(z^{2}-\overline{z^{2}}\right)+c_{22}\left(n^{2}-\overline{n^{2}}\right)+c_{12} z n .
$$

The factor levels of mechanical compression - current density sub-region and cell's delivered power, and also the factor levels of temperature - current density subregion and the cell's delivered power are shown in the

\begin{tabular}{|c|c|c|c|c|}
\hline \multirow[b]{2}{*}{$y$} & $X$ & 0.4 & 0.45 & 0.5 \\
\hline & & -1 & 0 & +1 \\
\hline 0.35 & -1 & 19.5 & 20 & 18.5 \\
\hline 0.45 & 0 & 21 & 22 & 21 \\
\hline 0.55 & +1 & 20.5 & 21 & 20 \\
\hline
\end{tabular}
table 1 and table 2, respectively.

Table 1: Factor levels of mechanical compression - current density subregion 
Table 2: Factor levels of temperature - current density subregion

\begin{tabular}{|l|c|l|l|l|}
\hline \multicolumn{2}{|c|}{$Z$} & & & \\
\cline { 3 - 5 }$n$ & & & 0.5 & 0.7 \\
\cline { 3 - 5 } & -1 & 0 & +1 \\
\hline $40^{\circ} \mathrm{C}$ & -1 & 26 & 25.5 & 20 \\
\hline $55^{\circ} \mathrm{C}$ & 0 & 25.25 & 27 & 23 \\
\hline $70^{\circ} \mathrm{C}$ & +1 & 23.5 & 24.2 & 22.2 \\
\hline
\end{tabular}

The matrix of the $2^{3}$ factorial experiment design is shown in the table 3 .

\section{A. The Response Surface of Mechanical Compression}

Taking into account the matrix of the experiment design given in table 3 , the coefficients of the response surface $f(x, y)$ are given by the following relations:

$$
\begin{gathered}
b_{0}^{\prime}=\frac{19.5+18.5+20.5+20+21+21+20+21+22}{9}=20.4 \\
b_{1}=\frac{-19.5+18.5-20.5+20-21+21}{6}=-0.25 \\
b_{2}=\frac{-19.5-18.5+20.5+20-20+21}{6}=0.58 \\
b_{11}=\frac{\frac{1}{3}(19.5+18.5+20.5+20+21+21)-\frac{2}{3}(20+21+22)}{6\left(\frac{1}{3}\right)^{2}+3\left(-\frac{2}{3}\right)^{2}}=-0.92 \\
b_{22}=\frac{\frac{1}{3}(19.5+18.5+20.5+20+20+21)-\frac{2}{3}(21+21+22)}{2}=-1.41 \\
b_{12}=\frac{19.5-18.5-20.5+20}{4}=-0.125
\end{gathered}
$$

Response surface equation for the mechanical compression - current density sub-region will be:

$$
f(x, y)=22-0.25 x+0.58 y-0.92 x^{2}-1.41 y^{2}-0.125 x y
$$

In figure 4 is shown the contour plot of the response surface for the mechanical compression and in figures 5 and 6 are shown several delivered power dependences of current density and of mechanical compression, respectively.

The natural values of the current density $X$, in $\mathrm{A} / \mathrm{cm}^{2}$, taking into account the factor's correspondence with the coded values $x$ of Table 1 , can be obtained with the formula:

$$
X=0.05 x+0.45
$$

In the same way can be obtained the natural values of the percent values of the mechanical compression $Y$ from the coded values y given in the Table 1:

$$
Y=0.1 y+0.45
$$

From the diagrams of Figure 6 one can determine the optimal value of the mechanical compression $Y_{\text {opt }}$ at the considered fuel cell temperature $\left(55^{0} \mathrm{C}\right)$. By using the last formula, this optimal value is of $48 \%$.

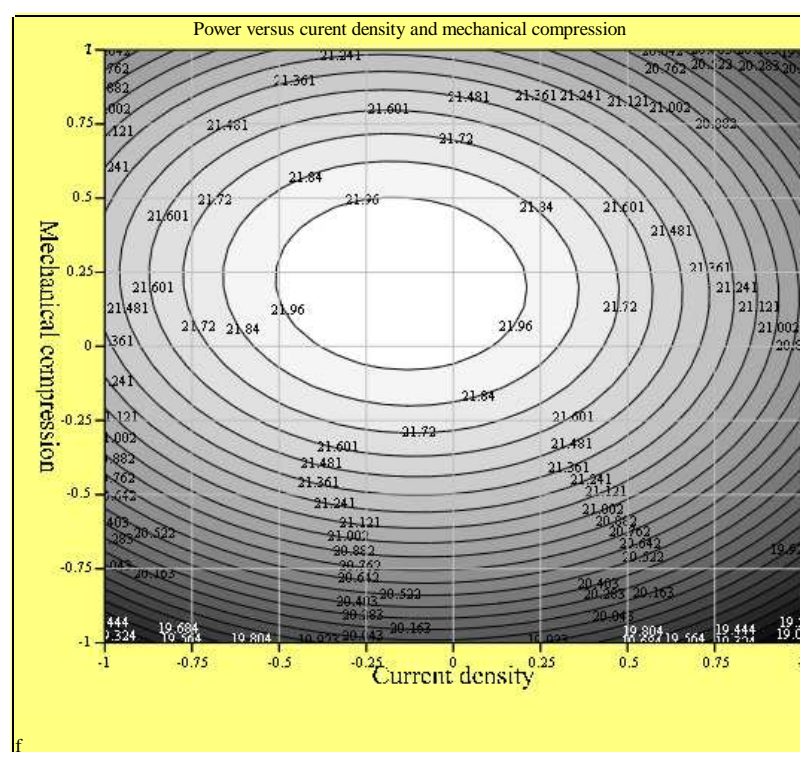

Fig. 4 Contour plot of the response surface for the mechanical compression

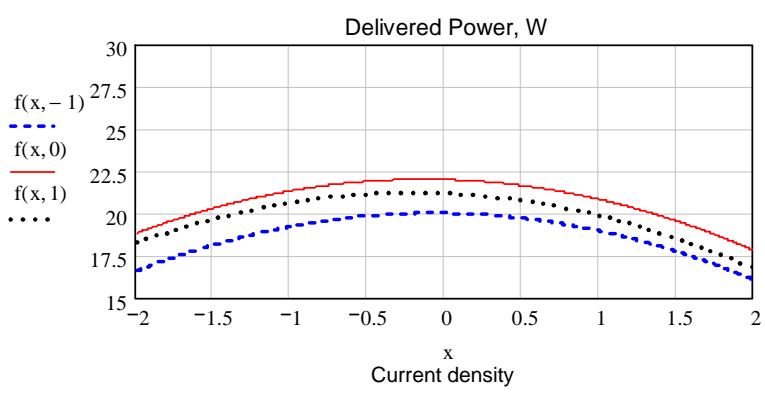

Fig. 5 Fuel Cell delivered power versus current density for three levels of mechanical compression



Fig. 6 Fuel Cell delivered power versus mechanical compression for three levels of current density

\section{A. The Response Surface of Fuel Cell Temperature}

The coefficients of the response surface $h(z, n)$, taking into account the matrix of the experiment design given in table 3 , are given by the following relations:

$$
\begin{gathered}
c_{0}^{\prime}=\frac{26+20+23.5+22.2+25.2+23+25.5+24.2+27}{9}=24 \\
c_{1}=\frac{-26+20-23.5+22.2-25.2+23}{6}=-1.58
\end{gathered}
$$




$$
\begin{gathered}
c_{2}=\frac{-26-20+23.5+22.2-25.5+24.2}{6}=-0.26 \\
c_{11}=\frac{\frac{1}{3}(26+20+23.5+22.2+25.2+23)-\frac{2}{3}(25.5+24.2+27)}{6\left(\frac{1}{3}\right)^{2}+3\left(-\frac{2}{3}\right)^{2}}=-2.25 \\
c_{22}=\frac{\frac{1}{3}(26+20+23.5+22.2+25.5+24.2)-\frac{2}{3}(25.2+23+27)}{2}=-1.5 \\
c_{12}=\frac{26-20-23.5+22.2}{4}=1.17
\end{gathered}
$$

Response surface equation for the temperature - current density sub-region will be:

$$
h(z, n)=26.5-1.58 z-0.26 n-2.25 z^{2}-1.5 n^{2}+1.17 z n
$$

In figure 7 is shown the contour plot of the response surface for the temperature and in figures 8 and 9 are shown several delivered power dependences of current density and of fuel cell temperature, respectively.

The natural values of the current density $Z$, in $\mathrm{A} / \mathrm{cm}^{2}$, taking into account the factor's correspondence with the coded values $z$ of Table 2, can be obtained with the formula:

$$
Z=0.1 z+0.6
$$

In the same way can be obtained the natural values of the fuel cell temperature $N$ from the coded values $n$ given in the Table 2:

$$
N=15 n+55
$$

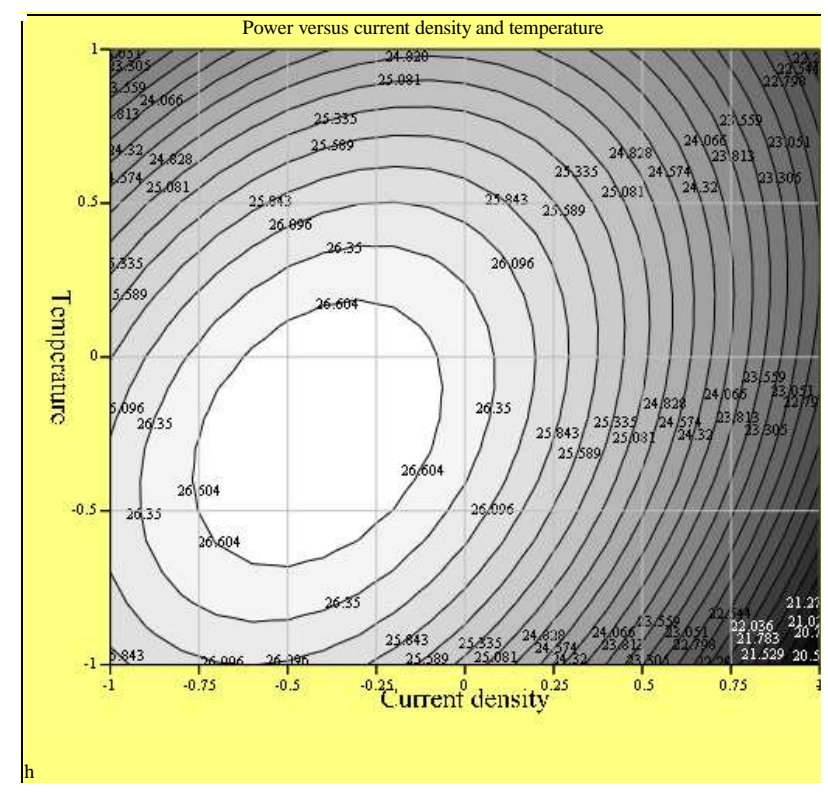

Fig. 7 Contour plot of the response surface for the fuel cell temperature

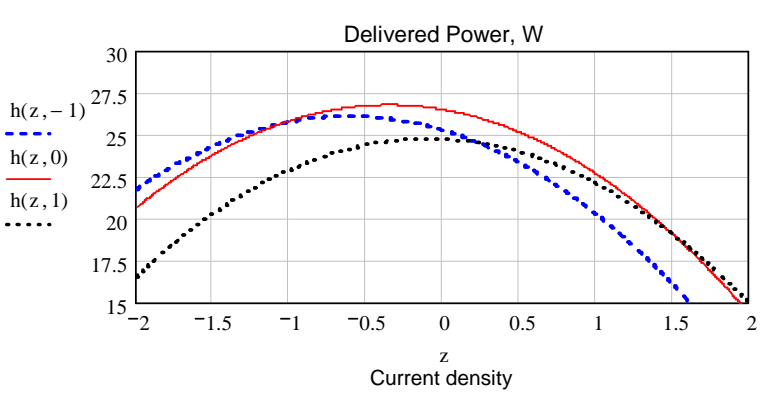

Fig. 8 Fuel Cell delivered power versus current density for three levels of the fuel cell temperature

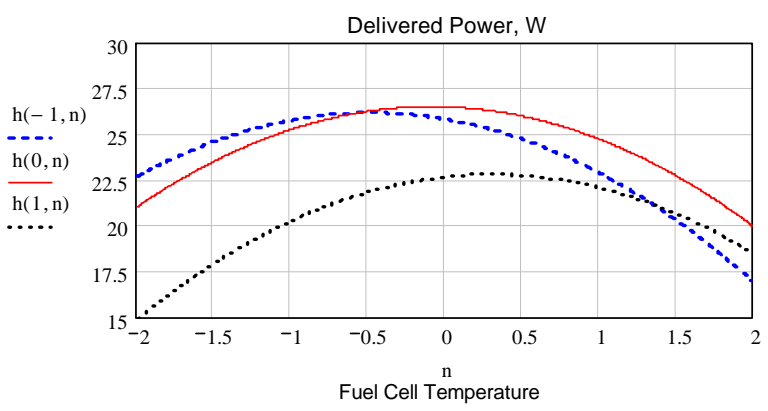

Fig. 9 Fuel Cell delivered power versus the fuel cell temperature for three levels of current density

\section{Conclusion}

Design of Experiment methodology provides a very efficient method to obtain a polynomial optimization model for the studied multivariable PEM Fuel Cell system.

\section{References}

[1] J. E. Larminie and A. Dicks, Fuel Cell Systems Explained, Chichester, John Wiley and Sons, 2000.

[2] D. C. Montgomery, Design and Analysis of Experiments, John Wiley and Sons, 2001.

[3] L. Pătularu, D. Stoenescu, M. Culcer, D. Mirica, G. R. R. Ionete and I. Stefanescu, Low power PEM Fuel Cells Development within ICIT-Rm. Vâlcea, Int. Conf. ECAI 2007, Univ. of Pitesti, ECAI'07, Nr.3/2007, ISSN-1843-2115.

[4] M. Ordonez, M. Tariq Iqbal, J. E. Quaicoe and L. M. Lye, Modelling and Optimization of Direct Methanol Fuel Cells Using Statistical Design of Experiment Methodology, IEEE CCECE/CCGEI, Ottawa, May, 2006, pp. 1120-1124.

[5] B. A. Ivobotenco, N. F. Ilinschii și I. P. Kopâlov, Planirovanie eksperimenta v electromehanike, Energhia, Moscova, 1975, 185 pag. 
Table 3. The matrix of the $2^{3}$ factorial experiment design

\begin{tabular}{|c|c|c|c|c|c|c|c|c|}
\hline \multirow{2}{*}{ Runs } & \multicolumn{7}{|c|}{$x_{i}$} & \multicolumn{2}{c|}{$P, \mathrm{~W}$} \\
\cline { 2 - 9 } & $x_{0}$ & $x_{1}$ & $x_{2}$ & $x_{3}^{\prime}=x_{1}^{2}-\frac{2}{3}$ & $x_{4}^{\prime}=x_{2}^{2}-\frac{2}{3}$ & $x_{5}=x_{1} x_{2}$ & $P_{\text {m. com. }}$ & $P_{\text {Temp }}$ \\
\hline 1 & +1 & -1 & -1 & $+1 / 3$ & $+1 / 3$ & +1 & 19.5 & 26.0 \\
\hline 2 & +1 & +1 & -1 & $+1 / 3$ & $+1 / 3$ & -1 & 18.5 & 20.0 \\
\hline 3 & +1 & -1 & +1 & $+1 / 3$ & $+1 / 3$ & -1 & 20.5 & 23.5 \\
\hline 4 & +1 & +1 & +1 & $+1 / 3$ & $+1 / 3$ & +1 & 20.0 & 22.2 \\
\hline 5 & +1 & -1 & 0 & $+1 / 3$ & $-2 / 3$ & 0 & 21.0 & 25.2 \\
\hline 6 & +1 & +1 & 0 & $+1 / 3$ & $-2 / 3$ & 0 & 21.0 & 23.0 \\
\hline 7 & +1 & 0 & -1 & $-2 / 3$ & $+1 / 3$ & 0 & 20.0 & 25.5 \\
\hline 8 & +1 & 0 & +1 & $-2 / 3$ & $+1 / 3$ & 0 & 21.0 & 24.2 \\
\hline 9 & +1 & 0 & 0 & $-2 / 3$ & $-2 / 3$ & 0 & 22.0 & 27.0 \\
\hline
\end{tabular}

